ZOOLOGIA 30 (5): 482-490, October, 2013

http://dx.doi.org/10.1590/S1984-46702013000500003

\title{
Socio-economic and spatial determinants of anthropogenic predation on Yellow-spotted River Turtle, Podocnemis unifilis (Testudines: Pelomedusidae), nests in the Brazilian Amazon: Implications for sustainable conservation and management
}

\author{
Darren Norris ${ }^{1,2} \&$ Fernanda Michalski² \\ ${ }^{1}$ Coordenação de Biodiversidade, Instituto Nacional de Pesquisas da Amazônia. Caixa Postal 478, 6901 1-970 Manaus, AM, \\ Brazil. Corresponding author. E-mail: dnorris75@gmail.com \\ ${ }^{2}$ Laboratório de Ecologia e Conservação de Vertebrados, Programa de Pós-graduação em Biodiversidade Tropical, \\ Universidade Federal do Amapá. Rodovia Juscelino Kubitscheck, km 02, 68902-280 Macapá, AP, Brazil.
}

\begin{abstract}
Human expansion has drastically affected wildlife species across Amazonian waterways and the continued increase in rural populations across Amazonia is likely to increase pressure on widely exploited chelonian species. The lack of information evaluating determinants of human consumption patterns limits the effective implementation of conservation strategies. Our objective was to determine the relative importance of social, economic, and spatial variables on human exploitation of Podocnemis unifilis Troschel, 1848 around a sustainable-use protected area in the eastern Brazilian Amazon. We conducted interviews with 51 riverine residents to evaluate attitudes towards and exploitation of $P$. unifilis. We used multimodel inference to evaluate 12 working hypothesis predicting social, economic, and spatial influences on the occurrence and intensity of $P$. unifilis egg consumption. None of the respondents reported catching and/or eating adult $P$. unifilis and none sold adults or eggs during the previous year. Although the majority (58.8\%) of respondents had eaten $P$. unifilis eggs during the previous year and the species was occasionally caught in fishing nets, $P$. unifilis was rarely cited as a liked or disliked species. Our information theoretic analysis showed that spatial hypotheses were the most strongly supported whereas social and economic hypotheses were only weakly supported in explaining if and how many P. unifilis eggs had been consumed by riverine residents during the previous year. Our findings suggest that current Amazonian development patterns may be associated with reduced consumption of adult $P$. unifilis, but consumption of eggs together with other indirect anthropogenic perturbations continue to threaten remaining $P$. unifilis populations.
\end{abstract}

KEY WORDS. Egg consumption; human impact; management programmes; nest predation; turtle conservation.

The increase and expansion of human populations means that biodiversity and species conservation activities are intrinsically associated with the socio-economic context (MARSHALL et al. 2007, Dickman 2010). Currently, almost 37\% of the Brazilian Amazon receives legal protection, with approximately $80.4 \%\left(\mathrm{H}^{\prime \prime} 1.6\right.$ million $\left.\mathrm{km}^{2}\right)$ of the protected areas in Brazilian Amazonia allowing some form of human use (Peres 2011). The increase in the number and extent of sustainable-use reserves (Peres 2011) means that the local success of protected areas for effective biodiversity conservation depends largely on ensuring the integration of local communities with activities aimed at conserving wildlife species and ecological processes.

The continued increase in rural populations across Amazonia is increasing pressure on widely exploited wildlife species. With Amazonian development centred around waterways, aquatic and semi-aquatic wildlife species are heavily impacted by anthropogenic perturbations even in apparently "remote" Amazonian locations (Peres 2000, 2011). For example a conservative (i.e. values are likely to be underestimates) analysis of data collected in the 80's and 90's suggested that between 39,793 and 95,111 adult Podocnemis unifilis Troschel, 1848 were consumed annually by low-income families across the Brazilian Amazon (Peres 2000). Riverine residents, also called "Ribeirinhos", form the largest ethnic group of rural Amazonian populations (Piperata 2007) and, since the analysis of Peres (2000), the rural population density across the Brazilian Amazon has generally remained stable or has increased (IBGE 2010, supplemental material S1). Therefore, not only has the pressure from human populations remained or increased, but declines in P. expansa populations are also thought to have caused increased consumption of the smaller bodied $P$. unifilis across the Amazon (Sмiтh 1979,Vogt 2008). The synergistic and/or 
additive interactions of these factors generate as yet unquantified threats to this species currently classified as Vulnerable (A1acd) by the IUCN (Tortoise \& Freshwater Turtle Specialist Group 1996).

Integration with local communities and stakeholders has generated success for chelonian conservation, including data collection (Martin \& James 2005, Townsend et al. 2005, Mogollones et al. 2010, NorRis et al. 2011), head starting projects (Hernández et al. 2010) and incentive payments (Ferraro \& GJERTSEN 2009). In the case of Amazon river turtles, the development of effective education and awareness activities are seen as vital to ensure that consumptive use of $P$. unifilis is sustainable and does not cause the same disastrous impacts on populations as seen in the co-genera P. expansa (Vogt 2008).

Although urbanization is generating a so called "nutrition transition" across the Brazilian Amazon (NARDoto et al. 2011), fish and fishing activities remain an important component of rural ribeirinho diet and culture (Dorea 2003, Piperata 2007). This association with Amazonian rivers means that although ribeirinhos may not necessarily depend on chelonians (a less predictable food source compared with fish species) for subsistence, the consumptive use of chelonians remains an important part of ribeirinho diet and culture across Amazonia (Dorea 2003, Kemenes \& Pezzuti 2007, Vogt 2008).

Here we investigated ribeirinho attitudes towards $P$. unifilis in eastern Amazonia using semi-structured interviews. Our objective was to determine the relative importance of social, economic, and spatial variables on human exploitation of $P$. unifilis around a sustainable-use protected area. We focused on aspects, which are likely to be important for the effective development of environmental education programs aimed at the conservation of $P$. unifilis and other Amazonian chelonians. We discuss the implications of socio-economic and spatial factors that affect $P$. unifilis nest predation and how changing patterns of Amazonian development may influence conservation management of threatened species.

\section{MATERIAL AND METHODS}

This study was conducted around the National Forest of Amapá ("Floresta Nacional do Amapá", hereafter FLONA),

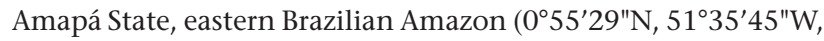
Fig. 1). FLONA is a 412,000 ha sustainable-use reserve. This protected area experiences relatively low levels of anthropogenic perturbations because only eight families live on the reserve border, and the nearest town (Porto Grande) is located $46 \mathrm{~km}$ by river from the reserve border (Fig. 1). The most recent census of the rural and total population in the municipality of Porto Grande provides an estimate of 6066 and 16825 inhabitants, respectively (IBGE 2010). Although population density across Brazilian Amazonia ranges widely (from $<1$ to $>1000$ inhabitants per $\mathrm{km}^{2}$ ), the population density in our study area appears to be fairly representative considering the densi-

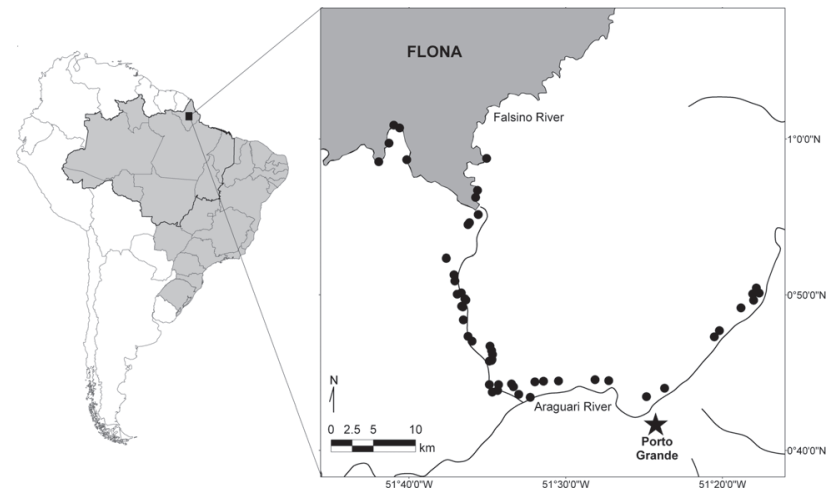

Figure 1. Location of the study area in Amapá State, eastern Brazilian Amazon. The location of the 51 interviews (solid circles) conducted between March, 2011 and May, 2012, and the nearest urban centre (Porto Grande - solid star). The shaded polygon shows the limits of the National Forest of Amapá (FLONA) and lines the centre of the Falsino and Araguari river channels.

ties from all nine states of the legal Brazilian Amazon (IBGE (2010), Fig. 2). We therefore believe that our study region is representative of the most frequently encountered human population density across Brazilian Amazonia (Fig. 2).

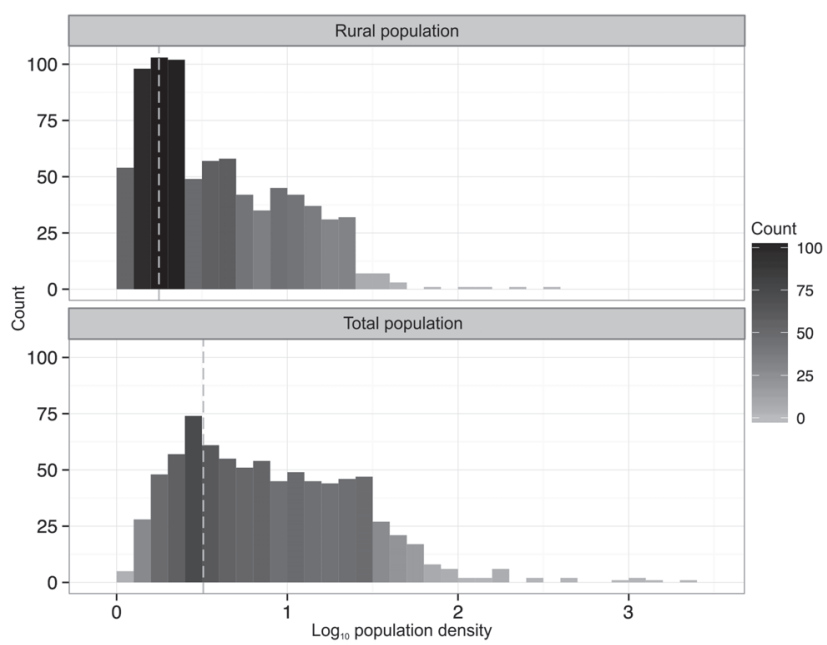

Figure 2. Frequency distribution of the rural and total population density (inhabitants per $\mathrm{km}^{2} \log _{10}$ ) from the 807 municipalities within the Legal Brazilian Amazon's nine states (Acre, Amapá, Amazonas, Pará, Rondônia, Roraima, Tocantins, Mato Grosso, and Maranhão) for 2010 (IBGE 2010). Vertical dashed lines indicate the rural and total population densities $\left(\log _{10}\right)$ of our study region.

From March 2011 to May 2012 we used pre-elaborated questionnaires to interview all riverine residents (hereafter ribeirinhos) that were based along the Araguari and Falsino 
Rivers (Fig. 1). The interviews were conducted on a one to one basis at the riverine residences with researchers asking questions and taking notes of ribeirinho responses.

As a key prerequisite, all residences that we visited were associated with one local informant (usually a long-term resident and or landowner), who was 1) willing to be interviewed and 2) had been living in the property or close to it for at least one year (mean $\pm \mathrm{SD}=15.3 \pm 13.2$ years, range $=1.0$-51.0 years; $\mathrm{n}=51$ respondents). In all cases, interviews were aided by colour plates in field guides or photographs. To ensure the reliability of the replies respondents were asked to identify which species were present in the region from a selection of mammal and reptile species of which three were known to be entirely absent from the study region. In over 150 trials, interviewees never falsely identified species as present that were known to occur only in other Neotropical regions, which gives us confidence that the data they provided for these species were reliable.

To understand attitudes towards $P$. unifilis we focused on replies to three questions. To avoid "leading" respondents replies, these questions did not specifically refer to $P$. unifilis, but rather considered attitudes towards wildlife species in general: 1) List five "liked" wild animal species, with species ranked according to the order in which they were mentioned (e.g. first mentioned species was the most liked). 2) List five "disliked" wild animal species, with species ranked according to the order in which they were mentioned (e.g. first mentioned species was the most disliked). 3) Which five wild animal species damage (directly or indirectly) fishing activity, with species ranked according to the order in which they were mentioned (e.g. first mentioned species was the most damaging).

We used answers to two questions as responses to examine the occurrence and intensity of ribeirinhos' egg consumption. We also asked whether respondents had sold either eggs or adult $P$. unifilis during the last year. As none of the respondents reported selling either eggs or adults we are confident that the "collection" of eggs reported in our study represents consumption by the respondent and/or their family: 1) Occurrence - Did you collect $P$. unifilis eggs during the last year? 2) Intensity How many $P$. unifilis nests did you collect in the last year?

To understand the reported patterns of egg consumption we used as explanatory variables replies from our pre-elaborated questionnaires that characterized the respondents, such as age, years of school education, and the principal source of income, all of which may be expected to influence consumption of $P$. unifilis eggs. As we were only able to uncover one published study describing predictors of local consumption of freshwater turtle eggs (RebêLo \& Pezzuti 2000) we selected a total of 12 economic, social, and spatial variables that based on a number of working hypothesis could be expected to influence egg consumption (Table I).

Generalized linear models (GLMs) were used to understand how the explanatory variables influenced the occurrence (i.e. if respondents ate eggs) and intensity (i.e. how many eggs were eaten) of nest predation. The responses of occurrence (GLM family = binomial, link $=\log )$, and intensity (GLM family = negative binomial, link $=\log$ ) were modelled separately to examine the relative importance of the economic, social, and spatial variables. With no $a$ priori justification to support variable inclusion we adopted a two stage information theoretic model averaging framework (Burnham \& ANDERson 2002) to examine relative importance of our 12 explanatory variables. Firstly the economic, social, and spatial variables were modelled separately to identify the most strongly supported variable in each category. We then selected the most important variable identified from each category (economic, social, and spatial) plus the variable with the next strongest weight of support from any of the three categories. This provided a total of four variables that were used to model each response and test the working hypotheses proposed to explain ribeirinhos' predation on turtle nests (Table I).

The information theoretic model averaging framework adopted enables multimodel inference where our GLMs were ranked and scaled by an information criterion to allow an understanding of model uncertainty over the set of candidate models (Burnham \& ANDERSON 2002: 281-284). We evaluated models based on their information content, as measured by AIC (Akaike Information Criteria implemented in R package "MuMIn" - BARTON 2011). With a strong a priori justification for inclusion, we retained all explanatory variables and all possible candidate models; therefore, all variables were on equal footing to calculate their relative importance as measured by variable Akaike weights (BURNHAM \& ANDERSON 2002: 75-77, 167 172), which is a scaled measure of the likelihood ratio that ranges between 0 (least important) and 1 (most important). A reduced subset of models for a 95\% confidence set, based on the sum of Akaike weights across all models from largest to smallest that resulted in the sum of 0.95 , was used to calculate average values for slopes (Burnham \& Anderson 2002: 169, 176177). To reduce model selection bias model averaging was carried out using the full set of confidence models i.e. when a predictor was not present in the model its value was set to 0 (BURNHAM \& ANDERSON 2002: 152).

\section{RESULTS}

\section{Attitudes towards $P$. unifilis}

Our interview data covered a broad diversity of ribeirinhos (Table II), e.g. ranging from young to elderly (mean age $=52$, range $=24-75$ years) and small to large families (mean family size $=3.7$, range $=1-10$ people). This ensures that we captured the widest possible variation of ribeirinhos perceptions towards fresh-water chelonians in our study region, which is a fairly representative region of the Brazilian Amazon in terms of rural and total population density (Fig. 2).

We initially examined the most commonly "liked" and "disliked" species obtained in our interviews. Paca (Cuniculus 
Table I. Working hypotheses and variables used to explain consumption of $P$. unifilis eggs by ribeirinhos in the eastern Brazilian Amazon.

\begin{tabular}{|c|c|c|c|c|}
\hline Category & Working hypothesis & Variable name & Variable description & $\begin{array}{l}{ }^{\text {a }} \text { Variable } \\
\text { support }\end{array}$ \\
\hline Economic & $\begin{array}{l}\text { Those earning more will be less likely to } \\
\text { consume eggs for subsistence. }\end{array}$ & Total income & Continuous - total monthly income. & - \\
\hline Economic & $\begin{array}{l}\text { Different occupations have different diets and } \\
\text { will have different patterns in egg consumption. }\end{array}$ & Primary income source & Categorical - 3 classes: fishing, agriculture, other. & + \\
\hline Economic & $\begin{array}{l}\text { Interaction between income and income source } \\
\text { will lead to differences in egg consumption. }\end{array}$ & Fishing income & $\begin{array}{l}\text { Continuous - total monthly income from fishing } \\
\text { activity. }\end{array}$ & + \\
\hline Economic & $\begin{array}{l}\text { More frequent fishers are more likely to } \\
\text { encounter nests and will therefore consume } \\
\text { more eggs. }\end{array}$ & Fishing frequency & Categorical - 3 classes: daily, weekly, monthly. & - \\
\hline Social & $\begin{array}{l}\text { Due to cultural differences those living longer in } \\
\text { the region will have different consumption } \\
\text { patterns. }\end{array}$ & Residence & $\begin{array}{l}\text { Continuous - proportion of years resident in the } \\
\text { region (time resident/age). }\end{array}$ & + \\
\hline Social & Larger families will consume more. & Family size & Continuous - number of family members. & + \\
\hline Social & $\begin{array}{l}\text { Differences in education will cause differences in } \\
\text { consumption patterns. }\end{array}$ & Education & $\begin{array}{l}\text { Categorical }-3 \text { classes of school education: illiterate, } \\
<6 \text { years, and } 6-10 \text { years. }\end{array}$ & - \\
\hline Social & $\begin{array}{l}\text { Due to cultural/social differences consumption } \\
\text { will differ with age. }\end{array}$ & Age & Continuous - age in years. & - \\
\hline Spatial & $\begin{array}{l}\text { Those living closer to the protected area will } \\
\text { consume less. }\end{array}$ & Zone & $\begin{array}{l}\text { Categorical - } 3 \text { classes based on proximity to the } \\
\text { protected area: close }(0-0.5 \mathrm{~km}) \text {, intermediate }(8.5 \\
-24.3 \mathrm{~km}) \text { and far }(27.3-42.4 \mathrm{~km}) \text {. }\end{array}$ & - \\
\hline Spatial & $\begin{array}{l}\text { Due to social/cultural behaviours (e.g. sharing) } \\
\text { consumption will be influenced by neighbours. }\end{array}$ & Neighbours consumption & $\begin{array}{l}\text { Continuous - number of nests consumed by nearest } \\
\text { neighbour. }\end{array}$ & ++ \\
\hline Spatial & $\begin{array}{l}\text { Due to social/cultural behaviours those with } \\
\text { closer neighbours will have different } \\
\text { consumption patterns. }\end{array}$ & Nearest neighbour distance & Continuous - distance to nearest neighbour (km). & - \\
\hline Spatial & $\begin{array}{l}\text { Those that travel further are more likely to } \\
\text { encounter nests. }\end{array}$ & Fishing distance & Continuous - distance usually travelled to fish (km). & + \\
\hline
\end{tabular}

Table II. Respondent profile. Characteristics of the 51 respondents interviewed.

\begin{tabular}{ll}
\hline \multicolumn{1}{c}{ Characteristic } & \multicolumn{1}{c}{ Respondent values } \\
\hline Gender $(\mathrm{n}, \%)$ & Male $(51,100)$ \\
Age (mean, range) & $52,24-75$ \\
Education ( $\mathrm{n}, \%)$ & None $(11,21.7),<6 \mathrm{yr}(32,62.7), 6-10$ \\
& $\mathrm{yr}(8,15.7)$ \\
Family size (mean, range) & $3.7,1-10\left[4.4^{\mathrm{b}}, 2-10^{\mathrm{b}}\right]$ \\
Fishing frequency (n,\%) & $\begin{array}{l}\text { Daily }(19,37.3), \text { weekly }(27,52.9), \\
\text { monthly }(5,9.8)\end{array}$ \\
Principal source of income (n,\%) & $\begin{array}{l}\text { Agriculture }(29,68.3), \text { fishing (10, } \\
22.0), \text { other }(12,9.8)\end{array}$ \\
Monthly income (median, range) & $500^{\mathrm{c}}, 0-7000^{\circ}\left[294^{\mathrm{d}}, 0-4118^{\mathrm{d}}\right]$ \\
\hline
\end{tabular}

a Includes only family members living at the property. ${ }^{b}$ Values excluding those who lived on their own. " Values in Brazilian Reais (R\$). At the time of interviews the legal minimum salary in Brazil was $\mathrm{R} \$ 545.00$ (Brazilian legal process number: 12.382/2011). ${ }^{\mathrm{d}}$ Values converted to US dollars (US\$), US $\$ 1.00=\mathrm{R} \$ 1.70$.

paca Linnaeus, 1766, $\mathrm{n}=27$ ), deer (Mazama spp., $\mathrm{n}=15$ ), collared peccary (Pecari tajacu Linnaeus, $1758, \mathrm{n}=11$ ) and "fish" ( $\mathrm{n}=10)$, were the most commonly "liked" species. Paca ( $\mathrm{n}=$ 16) and fish $(n=8)$ were the most frequently cited species to be first mentioned as liked. The most commonly cited reasons for liking wild animals were "good to eat" $(\mathrm{n}=34)$ and they are "beautiful" ( $\mathrm{n}=16)$. Only one respondent cited $P$. unifilis as a liked species (listed second after "fish").

The most disliked wild animals were snakes $(\mathrm{n}=28)$ and big cats (Panthera onca Linnaeus, 1758 and Puma concolor Linnaeus, $1771, \mathrm{n}=14$ ) and these were also the animals most frequently first mentioned as disliked $(\mathrm{n}=21, \mathrm{n}=8$, snakes and big cats respectively). Only one respondent cited $P$. unifilis as a disliked species. This respondent listed $P$. unifilis first and disliked it because it "was not eaten". Twenty-three (45.1\%) respondents reported that $P$. unifilis was (rarely) found in fishing nets and no respondent mentioned $P$. unifilis as a species that damaged fishing activities.

\section{Turtle egg consumption}

A total of 30 (58.8\%) respondents reported that they had eaten $P$. unifilis eggs during the previous year. The reported number of nests eaten during the last year ranged from 1 to 12 (mean $=2.96$ ). Assuming an average clutch size of 18 eggs (Table III) and considering the reported numbers of nests eaten this equated to a total of 89 nests/1602 eggs eaten annually. As most respondents $(40,78.4 \%)$ usually fished within $500 \mathrm{~m}$ of their residence we consider these values to represent consumption by the residents along $105 \mathrm{~km}$ of river, representing 0.8 
nests or 15.3 eggs consumed per river $\mathrm{km}$. None of the respondents reported catching and/or eating adult $P$. unifilis and none sold adults or eggs during the previous year. However, ribeirinhos confirmed during interviews that if turtles were accidentally captured in fishing nets, they consumed them. Thus, although adult $P$. unifilis did not appear to be targeted, adults could be eaten if captured accidentally during fishing activities, which was reported as a rare phenomenon.

Table III. Clutch size of Podocnemis unifilis obtained from the literature.

\begin{tabular}{|c|c|c|c|}
\hline River/basin & $\begin{array}{l}\text { Number } \\
\text { of nests }\end{array}$ & $\begin{array}{l}\text { Mean } \\
\text { clutch }\end{array}$ & Reference \\
\hline \multicolumn{4}{|l|}{ Brazil } \\
\hline Javaés River & 31 & 13.8 & 4.2 Ferreira \& Castro 2010 \\
\hline Javaés River & 35 & 13.1 & 4.5 Ferreira \& Castro 2010 \\
\hline Javaés River & 23 & 12.7 & 3.0 Ferreira \& Castro 2010 \\
\hline Javaés River & 25 & 13.4 & 2.8 Ferreira \& Castro 2010 \\
\hline Javaés River & 28 & 14.4 & 4.1 Ferreira \& Castro 2010 \\
\hline Javaés River & 16 & 12.1 & 3.2 Ferreira \& Castro 2010 \\
\hline Javaés River & 10 & 12.7 & 4.4 Ferreira \& Castro 2010 \\
\hline Javaés River & 6 & 12.8 & 3.1 Ferreira \& Castro 2010 \\
\hline Javaés River & 8 & 9.9 & 4.9 Ferreira \& Castro 2010 \\
\hline Solimões River & 28 & 35.1 & 5.9 TERAN et al. 2003 \\
\hline \multicolumn{4}{|l|}{ Colombia } \\
\hline Putumayo River & 12 & 27.3 & 5.7 FOOTE 1978 \\
\hline \multicolumn{4}{|l|}{ Venezuela } \\
\hline Nichare River basin & 21 & 18.8 & 4.8 Escalona \& Fa 1998 \\
\hline Nichare River basin & 43 & 23.3 & 5.8 Escalona \& Fa 1998 \\
\hline Nichare River basin & 9 & 21.3 & 6.1 Escalona \& Fa 1998 \\
\hline Nichare River basin & 30 & 19.9 & 4.8 EsCALONA \& FA 1998 \\
\hline Nichare River basin & 83 & 17.8 & 6.8 EsCALONA \& FA 1998 \\
\hline Nichare River basin & 43 & 19.3 & 6.7 Escalona \& Fa 1998 \\
\hline Nichare River basin & 193 & 21.0 & 5.2 Escalona \& Fa 1998 \\
\hline Capanaparo River & 22 & 23.3 & 4.6 ThORBJARNARSON et al. 1993 \\
\hline Mean & & 18.0 & \\
\hline
\end{tabular}

Our information theoretic analysis showed that the 12 variables used were more informative in explaining the binomial response of if eggs were consumed during the previous year $(\Sigma \mathrm{W}$ for all 12 variables: mean, range $=0.32,0.12-0.90)$ compared with the quantity of nests consumed ( $\Sigma \mathrm{W}$ for all 12 variables: mean, range $=0.25,0.06-0.57)$. This result was supported by the final GLM analysis (Table IV), which showed that our four "best" variables significantly explained variation in if eggs were consumed but not the quantity of nests predated.

Our GLMs showed similar patterns of variable importance for both responses, with spatial variables being the most important followed by economic then social (Fig. 3). Comparison of the sum of variable weights showed that spatial variables were clearly the most strongly supported for explaining if eggs were consumed ( $\Sigma W$ for all 4 variables: mean, range $=0.57,0.25-0.90)$ and the quantity of nests predated ( $\Sigma \mathrm{W}$ for all four variables: mean, range $=0.35,0.10-0.57$ ). Social and economic variables were generally only weakly supported, as $\Sigma \mathrm{W}$ did not rise above 0.33 for the social variables, and only once did an economic variable (Primary income source) have $\Sigma \mathrm{W}$ above 0.5 (Fig. 3).

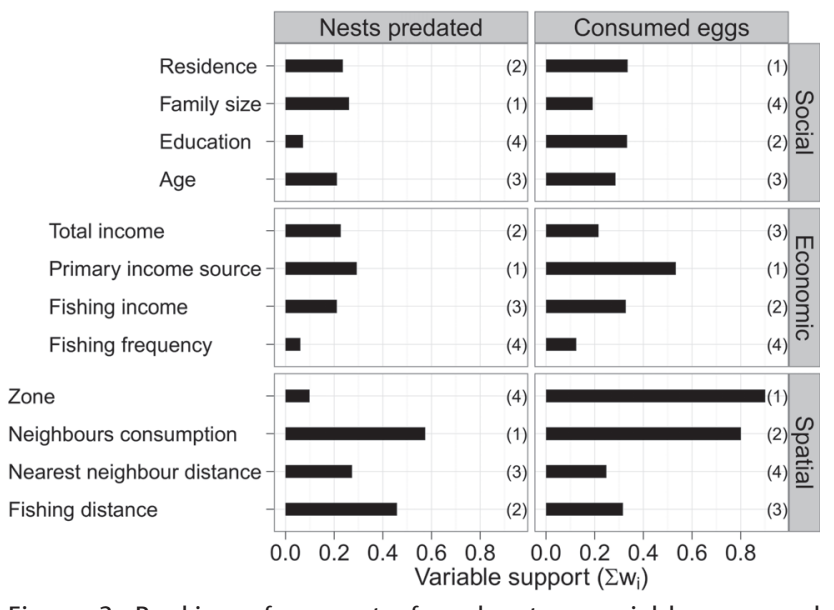

Figure 3. Ranking of support of explanatory variables grouped into three categories (Economic, Social and Spatial). The support of each variable within each model category was ranked (ranks in parenthesis) according to the sum of the Akaike weight $\left(\Sigma W_{i}\right)$ for their contribution to explain the responses of i) whether respondents consumed Podocnemis unifilis eggs during the previous year (Consumed eggs) and ii) how many nests the consumption of each respondent represented (Nests predated).

The final GLMs again showed the importance of spatial variables for explaining the consumption of $P$. unifilis eggs by ribeirinhos (Table IV). The number of eggs consumed by the nearest neighbour was the most important variable explaining both egg consumption and number of nests predated ( $\Sigma \mathrm{W} 0.85$ and 0.58 respectively). The other spatial (zone and fishing distance) variables were the second most strongly supported (0.69 and 0.44 , zone and fishing distance respectively), whereas the economic (primary income source) and social (residence time and family size) were only weakly supported ( $\Sigma W$ range $0.20-0.35$ ).

\section{DISCUSSION}

Human nest predation and egg consumption has long been recognised as both a threat (reducing recruitment and population size) and opportunity (a valuable resource, which generates stakeholder involvement in conservation) for the conservation and management of $P$. unifilis populations (Mittermeier 1978, Smith 1979, Caputo et al. 2005, Vogt 2008). Our results confirm findings of previous studies that showed 
Table IV. Model weights and parameter (slope) estimates from information-theoretic analysis of Podocnemis unifilis egg predation by riverine residents around a protected area (FLONA) in northeast Brazil. The four most relatively important of 12 "Social", "Economic" and "Spatial" variables were used to explain the responses of a) if respondents consumed $P$. unifilis eggs during the previous year ("Consumed eggs") and b) how many nests the consumption of each respondent represented ("Nests predated").

\begin{tabular}{|c|c|c|c|c|c|}
\hline \multicolumn{3}{|c|}{ Consumed eggs } & \multicolumn{3}{|c|}{ Nests predated } \\
\hline & Slope (SE) a & $\Sigma W_{i}{ }^{b}$ & & Slope (SE) a & $\Sigma W_{i}{ }^{b}$ \\
\hline Neighbours consumption & $0.294(0.159)$ & 0.85 & Neighbours consumption & $0.112(0.062)$ & 0.58 \\
\hline \multirow[t]{2}{*}{ Zone } & $0.248(0.924)^{r /}$ & 0.69 & Fishing distance & $-0.000(0.000)$ & 0.44 \\
\hline & $-1.508(0.910)^{\mathrm{rF}}$ & & Principal income & $-0.454(0.525)^{\mathrm{pF}}$ & 0.26 \\
\hline Residence & $1.699(1.728)$ & 0.35 & & $-0.802(0.459)^{p O}$ & \\
\hline \multirow[t]{2}{*}{ Principal income } & $-0.461(0.939)^{p F}$ & 0.24 & Family size & $0.043(0.071)$ & 0.20 \\
\hline & $-3.008(1.930)^{p o}$ & & & & \\
\hline Model Deviance explained (\%) & \multicolumn{2}{|c|}{22.05} & & \multicolumn{2}{|l|}{15.11} \\
\hline Model AIC & \multicolumn{2}{|c|}{67.87} & & \multicolumn{2}{|l|}{191.46} \\
\hline Model significance & \multicolumn{2}{|c|}{0.019} & & \multicolumn{2}{|l|}{0.079} \\
\hline
\end{tabular}

${ }^{a}$ Model averaged slope estimates for variables. ${ }^{\mathrm{b}}$ The sum of Akaike weights for all models within our set of candidate models with a given variable. Model averaging was carried out using the full set of confidence models, i.e., when a predictor was not present in the model its value was set to 0 (BuRNHAM \& ANDERSON 2002: 152). ' Zone shows slopes of responses from respondents resident close to the protected area (FLONA) compared with those resident at intermediate $(\mathrm{rl})$ and $\operatorname{far}(\mathrm{r} F)$ distances. p Principal income shows slopes of responses from respondents whose principal income comes from agriculture compared with those whose primary income comes from fishing $(\mathrm{p} F)$ and other sources $\left(\mathrm{p}^{\circ}\right)$.

intense ribeirinho consumption of $P$. unifilis eggs across different Amazonian regions (Foote 1978, Smith 1979, Escalona \& FA 1998, Teran \& von Mülhen 2003, Caputo et al. 2005, Vogt 2008). Yet few previous studies have examined economic, social, or spatial influences on ribeirinho consumption of $P$. unifilis eggs (but see Rebêlo \& Pezzuti 2000). While a number of management actions exist to ensure the sustainability of ribeirinho egg consumption (ThorbjaRnarson et al. 2000, CAPUTO et al. 2005, Vogt 2008, Mogollones et al. 2010), our findings provide a timely reminder that the efficacy of these actions will be intrinsically linked to the local context.

\section{Attitudes towards $P$. unifilis}

Our results show a clear separation of perceptions and actions towards $P$. unifilis eggs and adult stages. Generally $P$. unifilis was rarely mentioned in interviews and did not appear to be considered important as a species that was liked, disliked, or impacted fishing. This lack of attention by ribeirinhos presents a challenge for educators. As how is it possible to encourage conservation when the stakeholders rarely consider the impacted species? As the majority of ribeirinhos consumed eggs, egg consumption may provide the only solution to this dilemma. Yet ribeirinhos did not appear to directly associate egg consumption with the species, as despite the fact that nearly $60 \%$ of respondents reported eating eggs in the previous year, $P$. unifilis was only mentioned twice as a "liked" or "disliked" species.

It maybe that low anthropogenic consumption of adult P. unifilis in the region enables a seasonally predictable supply of eggs from the current adult population, and the intense egg consumption has yet to be reflected in population declines. But with the human consumption of $P$. unifilis eggs undoubt- edly reducing population recruitment, a very relevant question for the conservation of the species is: how long will adult P. unifilis populations remain? The challenge for conservation educators is to prevent the perpetuation of ribeirinhos naive inductivism (i.e. P. unifilis eggs have always been here and therefore they will always be here) by demonstrating the link between egg consumption, drastic population collapses and the loss of eggs as a resource (Vogt 2008, Schneider et al. 2011). Indeed, our findings suggest that establishing such a link should be the focus of precautionary conservation education activities aiming to prevent human egg consumption generating catastrophic consequences for local and basin wide populations of $P$. unifilis.

\section{Turtle egg consumption}

Previous studies have shown that freshwater turtles and their eggs are consumed and considered a delicacy in many Amazonian areas (Vogt 2008, SCHNeider et al. 2011). However, rapid development of Amazonian regions may change population demographics, attitudes, patterns of consumption and nutrition (PIPERATA et al. 2011). Our findings showed that the ribeirinho population in our study area did not generally appear to consume or trade adult $P$. unifilis and our semi-structured interviews failed to uncover any suggestion that turtles were considered a delicacy. Although fishing activities may accidentally catch turtles, which in turn could be consumed by our interviewees, this was not a common phenomena. This suggests that current patterns of Amazonian development and associated nutritional changes (Piperata 2007, Piperata et al. 2011) may reduce demand for adult turtles. Therefore direct anthropogenic impacts on freshwater turtle populations (e.g. 
consumption of adults) may also decline. However, indirect impacts of nest predation, waterway development, and anthropogenic pollution of waterways (e.g. gravel extraction, gold mining activities, oil extraction, hydroelectric power generation) are likely to generate equally deleterious effects on $P$. unifilis populations, which have already been reduced throughout much of Amazonia (Sмiтh 1979, Vogt 2008).

Although the majority of respondents consumed eggs, adult $P$. unifilis were not generally consumed. Previously reported ribeirinho behaviour of capturing $P$. unifilis adults using trotlines and or harpoons (SMith 1979, SCHNeider et al. 2011) did not occur in our study region. Indeed adult $P$. unifilis did not appear to be directly targeted and were only occasionally captured as by-catch in fishing gillnets. Also, females do not appear to be captured when they lay eggs. It is of course possible that respondents did not reply truthfully regarding the consumption/capture of adults. However, based on replies where respondents openly admitted to eating eggs, but $P$. unifilis was not included as a "liked" species (i.e. was not one that was eaten) we are confident that our findings are a fair representation of $P$. unifilis consumption in the region. The low levels of adult consumption is encouraging for conservation activities as the adult phase of long lived turtles is important for population persistence (Congdon et al. 1994, Mogollones et al. 2010), yet the occurrence and intensity of egg consumption is cause for concern as it has been shown to cause drastic population reductions across Amazonia (see reviews by THORBJARNARSON et al. 2000 and Vоgт 2008), particularly when compared with the abundances reported by early Amazon explorers (MEDINA 1934, MitTERMEIER 1978, Johns 1987).

We found a similar level of egg consumption (89 nests by 30 respondents with a mean family size of 3.7 individuals, totalling 111 people) to that reported by CAPUTO et al. (2005) in Ecuador where 105 nests were consumed by a community of "48 adults, 8 adolescents and 45 children" (totalling 101 people). However, assuming an average of 18 eggs per nest these levels are 4 times less than those reported by ReBêLo et al. (2005), where trips around a protected area in Amazonas State, Brazil returned with an average of 213 P. unifilis eggs. There are two non-mutually exclusive explanations for these differences: differences in $P$. unifilis abundances and differences in harvest levels for personal and commercial use. The depletion of $P$. unifilis abundances around more developed areas is well documented and human egg consumption is therefore likely to decrease as a result of decreased abundances close to human settlements especially when alternative food sources are available (Piperata 2007, Piperata et al. 2011). RebêLo et al. (2005) found a 10 fold reduction in $P$. unifilis egg harvests close to human settlements, which was also related to a clear separation between the number of eggs collected for personal consumption and commercial trade. Such differences highlight the importance of understanding the role played by social and economic factors in the consumption of $P$. unifilis eggs.
Our findings showed that the consumption of $P$. unifilis eggs during the previous year was most strongly influenced by the spatial variables and only weakly by the economic and social variables examined. Our GLMs only weakly explained the number of nests consumed by ribeirinhos, with only one spatial variable (neighbours egg consumption) appearing to strongly influence this response. The weakness of the social and economic variables in predicting the occurrence and quantity of eggs consumed supports conclusions from previous studies that consumption of turtles/ turtle eggs is not necessary for ribeirinho subsistence (SCHNEIDER et al. 2011) and also suggests that this consumption does not necessarily form a strong part of $21^{\text {st }}$ century ribeirinho culture.

From 61 interviews conducted in and around a Brazilian state capital Rebêlo \& Pezzuti (2000) concluded that educated (> 10 years, predominantly university students) and more wealthy urban residents had lower consumption of turtles. However, such a wide spectrum in education and wealth is not typical in populations outside of Brazilian capital cities. Compared with $>2$ million residents in the urban centre of REBÊLO \& Pezzuti (2000) the closest town in our study region ("Porto Grande") has less than 20,000 residents and although our study did include some well educated (10 years) and relatively wealthy respondents they were a minority. We therefore consider our sample to represent a profile of population that is more generally found throughout Brazilian Amazonia.

The weakness of our social and economic explanatory variables could be explained by the relatively homogenous respondent profile of our study area compared with the study of RebêLo \& Pezzuti (2000). Yet the consumption of turtle eggs appears to be localised even within our relatively "homogenous" study area. A number of theories could be proposed to explain this pattern e.g. the exchange of information between neighbours regarding the location of nesting beaches and/or the exchange of collected eggs between close neighbours. Although further investigation is required to understand the detail of this localised consumption, what is clear is that the conservation and management actions for Amazonian chelonians need to be developed within the local socio-economic context (VOGT 2008).

\section{Concluding remarks and conservation implications}

Our study suggests that at a time of rapid Amazonian development, the intensity of human consumption of freshwater turtle eggs remains a challenge for conservation biologists around the increasing number of sustainable-use reserves. We showed that spatial variables such as the number of eggs consumed by the nearest neighbour were important explanatory variables of turtle egg consumption in our study region. This finding suggests that educational campaigns could be more effective if applied to localised areas of the study region, where egg consumption is greater.

Our results highlighting the low importance of economic and social variables in explaining turtle egg consumption cha- 
llenge the common assumption that more educated people would eat less turtles eggs (Rebêto \& Pezzuti 2000, Vogt 2008, SCHNEIDER et al. 2011). Although comparable data describing the importance of spatial, social, and economic variables in determining human consumption of turtle eggs remains scarce, the diversity of Amazonian population demographics and cultures means that understanding both the local socio-economic context and stakeholder attitudes must be a priority to ensure the long term success of Neotropical turtle conservation activities.

The rarity of both the consumption and trade of adult $P$. unifilis in our study region suggests that rural development patterns in relatively remote areas of the Brazilian Amazon may be affecting traditional cultures and that a more up to date approach should be used to develop relevant conservation management activities. We suggest that further studies exploring the relative contribution of social, economic and spatial variables in Amazonian areas representing different demographic profiles are likely to result in more effective and positive contributions for the conservation of threatened Neotropical chelonians.

\section{ACKNOWLEDGEMENTS}

This research was supported by Conservation International - Brazil, and the Walmart Institute - Brazil through the project "Support to the implementation of the Amapá National Forest", The Rufford Small Grants for Nature Conservation and a research grant from CNPq (process 477629/2011-3). The Instituto Chico Mendes de Conservação da Biodiversidade (ICMBIO) and the Universidade Federal do Amapá provided logistical support. We thank IBAMA for authorization to conduct research in FLONA (IBAMA/SISBIO permit 26653-1). DN receives a postdoctoral fellowship from CNPq (process 401370/ 2012-7). We are deeply indebted to all riverine residents that contributed to this study and to Paula Caroline Conceição, Joyce Araujo Amador, Juliana Laufer, Alvino Pantoja, and Dinael Soares for assistance in the field.

\section{LITERATURE CITED}

BARTON, K. 2011. MuMIn: Multi-model inference. Available online at: http://R-Forge.R-project.org/projects/mumin [Accessed: 23.XI.2012].

Burnham, K.P. \& D.R. Anderson. 2002. Model Selection and Multi-Model Inference: A Practical InformationTheoretic Approach. Springer, New York.

Caputo, F.P.; D. Canestrelli \& L. Boitani. 2005. Conserving the terecay (Podocnemis uinifilis, Testudines: Pelomedusidae) through a community-based sustainable harvest of its eggs. Biological Conservation 126: 84-92. doi: 10.1016/ j.biocon.2005.05.004.

Congdon, J.D.; A.E. Dunham \& R.C.V. Sels. 1994. Demographics of common snapping turtles (Chelydra-Serpentina) -
Implications for conservation and management of longlived organisms. American Zoologist 34: 397-408.

Dickman, A.J. 2010. Complexities of conflict: the importance of considering social factors for effectively resolving humanwildlife conflict. Animal Conservation 13: 458-466. doi: 10.1111/j.1469-1795.2010.00368.x.

DOREA, J.G. 2003. Fish are central in the diet of Amazonian riparians: should we worry about their mercury concentrations? Environmental Research 92: 232-244. doi: 10.1016/s00139351(02)00092-0.

Escalona, T. \& J.E. FA. 1998. Survival of nests of the terecay turtle (Podocnemis unifilis) in the Nichare-Tawadu rivers, Venezuela. Journal of Zoology 244: 303-312.

Ferraro, P. J. \& H. GJertsen. 2009. A Global Review of Incentive Payments for Sea Turtle Conservation. Chelonian Conservation and Biology 8: 48-56. doi: 10.2744/ccb-0731.1.

Foote, R.W. 1978. Nesting of Podocnemis unifilis (Testudines: Pelomedusidae) in the Colombian Amazon. Herpetologica 34: 333-339.

JoHns, A.D. 1987. Continuing problems for Amazon river turtles. Oryx 21 (1): 25-28. doi: 10.1017/S0030605300020445.

Hernández, O.; A.S. Espinosa-Blanco; L.C. May; M. Jiménez-OraA \& A.E. SEIJAS. 2010. Artificial incubation of yellow-headed sideneck turtle Podocnemis unifilis eggs to reduce losses to flooding and predation, Cojedes and Manapire Rivers, southern Venezuela. Conservation Evidence 7: 100-105.

IBGE. 2010. Censo demográûco 2010. Instituto Brasileiro de Geograûa e Estatística, Rio de Janeiro. Available online at: http://www.ibge.gov.br/home/download/estatistica.sht [Accessed: 13.I.2013].

Kemenes, A. \& J.C.B. Pezzuti. 2007. Estimate of trade traffic of Podocnemis (Testudines, pedocnemididae) from the middle Purus River, Amazonas, Brazil. Chelonian Conservation and Biology 6: 259-262. doi: 10.2744/1071-8443.

Marshall, K.; R. White \& F. Anke. 2007. Conflicts between humans over wildlife management: on the diversity of stakeholder attitudes and implications for conflict management. Biodiversity and Conservation 16: 31293146. doi: 10.1007/s10531-007-9167-5.

Martin, K. \& M.C. James. 2005. Conserving sea turtles in Canada: Successful community-based collaboration between fishers and scientists. Chelonian Conservation and Biology 4: 899-907.

Medina, J. 1934. The discovery of the Amazon according to the account of Friar Caspar de Carvajal (Oveido's version). In: HC. Heaton (Ed.). Special Publication 17. New York, American Geographical Society.

MitTermeIER, R.A. 1978. South America's river turtles: saving them by use. Oryx 14: 222-230. doi: 10.1017/S0030605300015532.

Mogollones, S.C.; D. J. Rodriguez; O. Hernandez \& G. R. Barreto. 2010. A demographic study of the arrau turtle (Podocnemis expansa) in the Middle Orinoco River, Venezuela. Chelonian Conservation and Biology 9: 79-89. doi: 10.2744/CCB-0778.1. 
Nardoto, G.B.; R.S.S. Murrieta; L.E.G. Prates; C. Adams; M.E.P.E. Garavello; T. Schor; A. De Moraes; F.D. Rinaldi; J.G. Gragnani; E.A.F. Moura; P.J. Duarte-Neto \& L.A. Martinelli. 2011. Frozen Chicken for Wild Fish: Nutritional Transition in the Brazilian Amazon Region Determined by Carbon and Nitrogen Stable Isotope Ratios in Fingernails. American Journal of Human Biology 23: 642-650. doi: 10.1002/ ajhb.21192.

Norris, D.; N.C.A. Pitman; J.M. Gonzalez; E. Torres; F. Pinto; H. Collado; W. Concha; R. Thupa; E. Quispe; J. Perez \& J.C. FloRES DEL CASTILlo. 2011. Abiotic modulators of Podocnemis unifilis (Testudines: Podocnemididae) abundances in the Peruvian Amazon. Zoologia 28: 343-350. doi: 10.1590/ s1984-46702011000300008.

Peres, C.A. 2000. Effects of subsistence hunting on vertebrate community structure in Amazonian forests. Conservation Biology 14: 240-253. doi: 10.1046/j.1523-1739.2000.98485.x.

Peres, C.A. 2011. Conservation in sustainable-use tropical forest reserves. Conservation Biology 25: 1124-1129.

Piperata, B.A. 2007. Nutritional status of Ribeirinhos in Brazil and the nutrition transition. American Journal of Physical Anthropology 133: 868-878. doi: 10.1002/ajpa.20579.

Piperata, B.A.; J.E. Spence; P. Da-Gloria \& M. Hubbe. 2011. The Nutrition Transition in Amazonia: Rapid Economic Change and its Impact on Growth and Development in Ribeirinhos. American Journal of Physical Anthropology 146: 1-13. doi: 10.1002/ajpa.21459.

Rebêlo, G.H. \& J.C. Pezzuti. 2000. Perceptions on Amazon Turtles consumption: sustainability and alternatives to present management. Ambiente \& Sociedade 3: 85-104.

Rebêlo, G.H.; J.C. Pezzuti; L. Lugli \& G. Moreira. 2005. P esca Artesanal de Quelônios no Parque Nacional do Jaú (AM). Boletim do Museu Paraense Emilio Goeldi 1 (1): 109-125.

Schneider, L.; C.R. Ferrara; R.C. Vogt \& J. Burger. 2011. History of Turtle Exploitation and Management Techniques to Conserve Turtles in the Rio Negro Basin of the Brazilian Amazon. Chelonian Conservation and Biology 10: 149-157.

Sмiтh, N.J.H. 1979. Aquatic turtles of Amazonia: an endangered resource. Biological Conservation 16: 165-176.

Teran, A.F. \& E.M. von Mülhen. 2003. Reproducción de la taricaya podocnemis unifilis troschel 1848 (testudines: podocnemididae) en la várzea del medio solimões, Amazonas, Brasil. Ecología Aplicada 2: 125-132.

Thorbjarnarson, J.B.; C.J. Lagueux; D. Bolze; M.W. Klemens \& A.B. MeYlan. 2000. Human use of turtles: a worldwide perspective, p. 33-84. In M.W. Klemens (Ed.). Turtle Conservation. Washington, D.C., Smithsonian Institution Press.

Tortoise \& Freshwater Turtle Specialist Group 1996. Podocnemis unifilis. In: IUCN Red List of Threatened Species. Version 2012.2. Availeable online at: http://www.iucnredlist.org. [Accessed: 10.I.2013].

Townsend, W.R.; R. Borman; E. Yiyoguaje \& L. Mendua. 2005. Cofan Indians' monitoring of freshwater turtles in Zabalo, Ecuador. Biodiversity and Conservation 14: 2743-2755. doi: 10.1007/s10531-005-8410-1.

Vogt, R. 2008. Tartarugas da Amazonia. Manaus, INPA.

Submitted: 31.I.2013; Accepted: 14.VIII.2013.

Editorial responsibility: Walter A.P. Boeger 